\title{
HEPATECTOMIA TOTAL COM PRESERVAÇÃO DA VEIA CAVA INFERIOR: "PIGGY-BACK" EXPERIMENTAL EM CÃES ${ }^{1}$
}

\section{TOTAL HEPATECTOMY WITH PRESERVATION OF THE INFERIOR VENA CAVA: PIGGYBACK TECHNIQUE IN THE DOG}

\author{
Orlando de Castro-e-Silva Jr' \\ Fernando S Ramalho ${ }^{3}$ \\ Eduardo G Pacheco ${ }^{4}$
}

\section{RESUMO}

No transplante de fígado, a preservação do segmento retro-hepático da veia cava durante a hepatectomia do receptor apresenta uma série de vantagens: diminuição do tempo de isquemia quente por eliminar a anastomose da veia cava infra-hepática, redução da necessidade da utilização de derivações veno-venosas e simplificação da cirurgia do re-transplante hepático. Em cães, os lobos hepáticos lateral direito e caudado são caprichosamente atravessados pela veia cava inferior, dificultando a completa "esqueletização" do vaso. No presente trabalho, os autores revisam a singular história do método do "piggy-back" experimental e clínico, e discutem a técnica da cirurgia em cães. Disponível em URL: http://www.scielo.br/acb

Descritores - Transplante hepático, Hepatectomia, "piggy-back", Veia cava inferior, Derivação venovenosa, Cão.

\begin{abstract}
During the recipient hepatectomy in liver transplantation, preservation of the retrohepatic segment of the inferior vena cava has several advantages: it decreases warm ischemia time by eliminating the infrahepatic caval anastomosis, eliminates the need for venovenous bypass and eases retransplantation. Removal of the liver of the dog without sacrificing the inferior vena cava has been
\end{abstract}

considered impossible because of the intrahepatic course of the vena cava at the sites of entry of the hepatic veins. The following report reviews the history of the piggyback method, and discuss about the feasibility of the total removal of the liver without injury to the vena cava in the dog.

Key Words - Piggyback; Hepatectomy; Liver transplantation; Venovenous bypass; Inferior vena cava; Dog.

\section{INTRODUÇÃO}

O transplante ortotópico do fígado é, na atualidade, o procedimento terapêutico de escolha para uma série de hepatopatias agudas e crônicas ${ }^{1}$. Desde o primeiro transplante em humanos realizado por Starzl em 1963, em Denver - EUA ${ }^{2}$, a técnica operatória vem sofrendo algumas modificações no sentido de se reduzir o tempo cirúrgico, com conseqüente redução da morbi-mortalidade do receptor. A cirurgia convencional no receptor inclui a hepatectomia total com remoção do segmento retro-hepático da veia cava inferior, exigindo a utilização de uma derivação veno-venosa externa temporária ("shunt" portocavajugular) durante a fase anepática ${ }^{3,4}$.

A técnica de preservação da veia cava inferior na hepatectomia durante o transplante de fígado, denominada de "piggy-back", foi inicialmente utilizada em cães por Fonkalsrud e cols. (1967) $)^{5}$, e no transplante clínico por Calne e cols. $(1968)^{6}$, mas somente a partir

1 Trabalho realizado no Departamento de Cirurgia e Anatomia - FMRP - USP

2 Prof. Dr. da Disciplina de Gastroenterologia do Departamento de Cirurgia e Anatomia da FMRP - USP

3 Docente da Disciplina de Anatomia do Departamento de Cirurgia e Anatomia da FMRP - USP

4 Pós-graduando da área de Clínica Cirúrgica do Departamento de Cirurgia e Anatomia da FMRP-USP 
dos trabalhos de Tzakis e cols. (1989) que o "piggyback" foi amplamente difundido ${ }^{7}$. Inicialmente preconizada para pacientes pediátricos hemodinamicamente instáveis, a técnica de "piggy-back" foi rapidamente extendida aos receptores pediátricos e adultos, constituindo-se, atualmente, na técnica cirúrgica mais utilizada pelos centros transplantadores de fígado em todo o mundo. Algumas de suas vantagens incluem a diminuição do tempo de isquemia quente por eliminar a anastomose da veia cava infra-hepática, a redução da necessidade da utilização de derivações veno-venosas e a simplificação da cirurgia do re-transplante hepático ${ }^{4,8}$.

Quando, entretanto, analisamos a cirurgia experimental do transplante de fígado, verificamos uma singular defasagem em relação ao transplante clínico. Em cães, a hepatectomia total com preservação da veia cava retro-hepática foi descrita em 1952 e 1959, respectivamente por Frank \& Jacob ${ }^{9}$ e por Starz ${ }^{10}$. Com o advento dos transplantes de fígado na década de 60 , a técnica, utilizada experimentalmente por Fonkalsrud e cols. $(1967)^{5}$ e clinicamente por Calne e cols. $(1968)^{6}$, foi curiosamente esquecida, ressurgindo apenas 20 anos mais tarde no transplante clínico, mas permanecendo fora dos laboratórios de cirurgia experimental até os dias atuais.

O presente trabalho objetiva revisar a singular história do "piggy-back" e discutir a técnica da cirurgia em cães.

\section{TÉCNICA CIRÚRGICA}

Cães mestiços adultos $(n=4)$, pesando entre 9 e 15 quilos, procedentes do Biotério Central do Campus de Ribeirão Preto da Universidade de São Paulo, foram anestesiados com pentobarbital sódico (Nembutal, Abbott Lab. Ltda.), à dose de $30 \mathrm{mg} / \mathrm{kg}$ de peso corporal, via endovenosa. Os animais foram submetidos a intubação endotraqueal, com respiração controlada em respirador Takaoka 600, a uma freqüência de 15 incursões por minuto, com oxigênio a $100 \%$. A hidratação intra-operatória foi realizada com solução fisiológica por meio de um cateter inserido na veia jugular externa (volume médio de $30 \mathrm{ml} / \mathrm{kg}$ de peso). A pressão arterial média foi continuamente monitorizada por meio de um cateter introduzido na artéria femoral esquerda.

Após a realização de laparotomia mediana xifopúbica, procedeu-se a inventário da cavidade abdominal com o objetivo de excluir animais com malformações evidentes. A abordagem do pedículo hepático foi inicia- da com a dissecção e a secção entre ligaduras do ducto biliar comum e da artéria hepática, permitindo a completa exposição da veia porta e de suas tributárias. Os ligamentos hepato-esofágico, hepato-gástrico, redondo, falciforme, triangulares e coronários foram também secionados. A veia cava inferior foi dissecada a partir da desembocadura da veia renal direita (em um caso, a veia adrenal direita foi secionada entre ligaduras)

Na seqüência, foi realizada uma ampla anastomose portocava latero-lateral ( $\sim 15 \mathrm{~mm}$ de diâmetro) com fio de polipropileno 5-0, sutura contínua, visando a descompressão do território esplâncnico após a ressecção do fígado, prescindindo do uso de derivações veno-venosas (Figura 1). Em seguida, por meio de cuidadosa dissecção, os lobos lateral direito e caudado foram afastados da veia cava inferior, permitindo a exposição de pequenas veias emergindo do parênquima hepático (cerca de 8 a 10 veias hepáticas acessórias), as quais foram ligadas ou suturadas rentes à parede da veia cava (Figura 1A). A maior das veias hepáticas acessórias (retro-hepáticas) se localizava logo acima da anastomose portocava, sendo geralmente a primeira veia a ser encontrada quando a dissecção progredia no sentido caudal-cranial.

Terminada a "esqueletização" da veia cava inferior, a veia porta foi ligada e secionada acima do "shunt" portocava (esse passo foi antecipado nos casos de sangramento do parênquima hepático). A última manobra se resumiu na dissecção e secção das veias hepáticas (direita, média e esquerda), seguida de sutura contínua do coto desses vasos com fio de polipropileno 4-0, com remoção do fígado (Figura 1B).

Todas as cirurgias foram completadas sem grandes complicações. A perda sanguínea foi reposta com solução fisiológica, garantindo a estabilidade hemodinâmica dos animais. A estase sanguínea no território portal se limitou ao período de confecção da anastomose portocava, não se observando edema de alças intestinais. O tempo cirúrgico variou entre 180 e 240 minutos. Os cães foram sacrificados logo após o término da cirurgia utilizando-se pentobarbital sódico.

\section{DISCUSSÃO}

A hepatectomia total experimental sem o sacrifício da veia cava retro-hepática tem sido considerada impossível por importantes transplantadores de fígado. Em cães, os lobos hepáticos lateral direito e caudado são caprichosamente atravessados pela veia cava inferior, dificultando a completa "esqueletização" do vaso ${ }^{11}$. Di- 


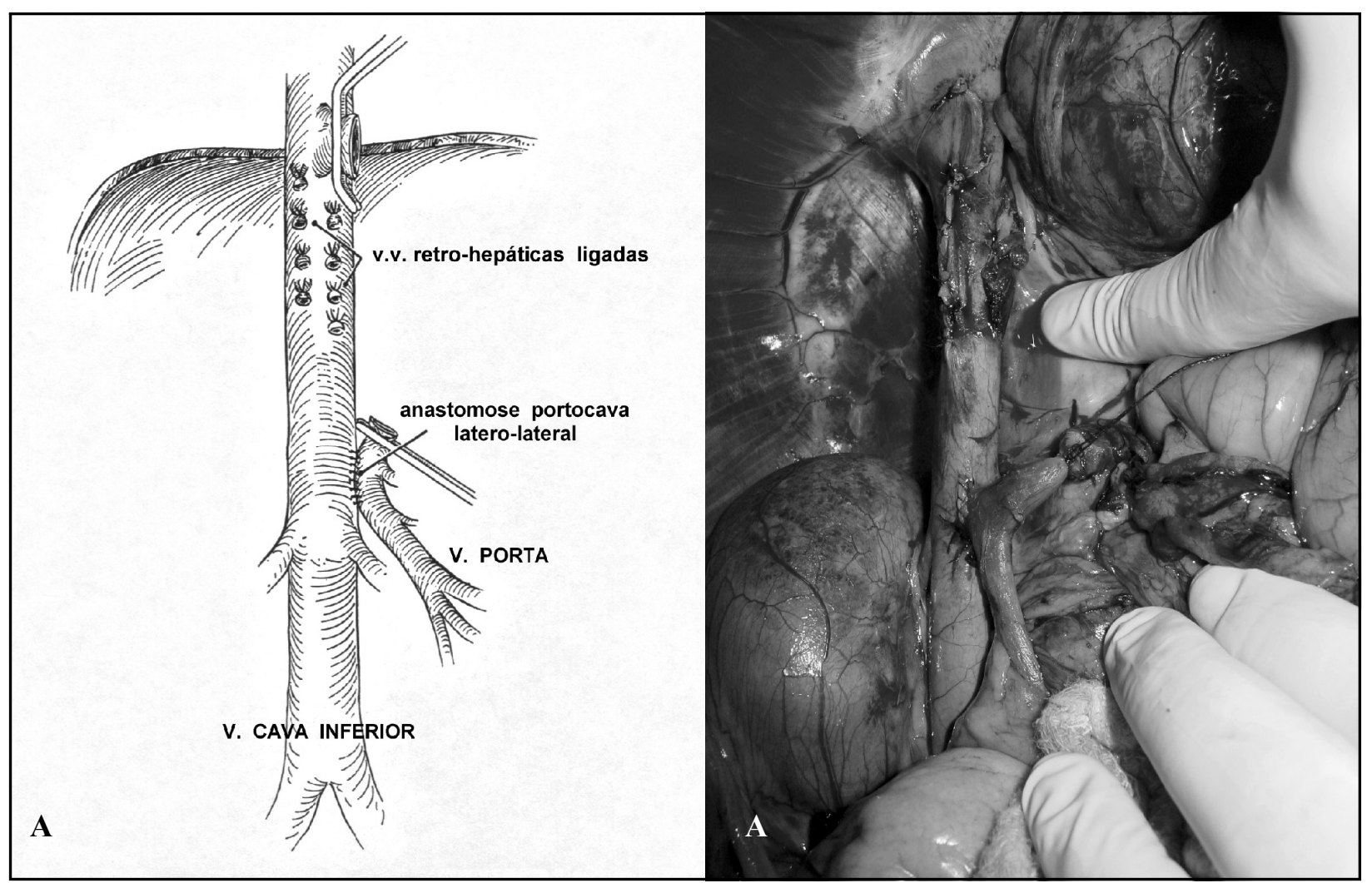

Figura 1 - Representação esquemática (A) e fotografia (B) demonstrando a técnica de preservação do segmento retro-hepático da veia cava inferior ("piggy-back"). São facilmente visualizadas a veia cava inferior, a veia porta e a anastomose portocava látero-lateral. As veias hepáticas acessórias (retro-hepáticas) foram ligadas individualmente. As veias hepáticas foram fixadas com "clamp" vascular (A) e suturadas com polipropileno 4-0 (B) (fig. 1a. - extraída de Fonkalsrud, 1967).

versas pequenas veias (veias hepáticas acessórias), algumas delas bastante calibrosas, comunicam o parênquima hepático à veia cava, tornando a técnica experimental pouco mais trabalhosa que a cirurgia em humanos. Dessa forma, a imensa maioria dos estudos experimentais envolvendo transplante de fígado utiliza a técnica cirúrgica convencional.

A ausência de circulação colateral nos animais saudáveis e o fato de cães não resistirem à completa oclusão da veia porta tornam imperiosa a utilização de uma derivação porto-sistêmica para a descompressão do território esplâncnico ${ }^{10}$. Optou-se pela confecção de uma anastomose portocava (fístula de Eck) ao invés de uma derivação externa com prótese (p.e. "shunt" portojugular) em virtude da heparinização do animal vir a comprometer possíveis estudos envolvendo o sistema da coagulação. A mesma limitação é observada quando são utilizadas derivações veno-venosas externas temporárias, geralmente "shunts" portocavajugulares, obrigatoriamente associados à técnica cirúrgica experimental convencional ${ }^{3}$. A anastomose portocava temporária é algumas vezes também empregada no transplante clínico, especificamente nos casos em que o receptor não possui circulação colateral eficiente (p.e. nos casos de insuficiência hepática aguda) $)^{4}$.

Outra vantagem do "piggy-back" em relação à cirurgia convencional diz respeito à possibilidade do implante de pequenos segmentos hepáticos, simulando o transplante inter-vivos ${ }^{12}$. A preservação da veia cava inferior é imprescindível nesse tipo de transplante, visto que o segmento hepático transplantado encontra-se, via de regra, desprovido de veia cava.

A técnica cirúrgica acima descrita constitui-se num fiel modelo experimental do transplante hepático clínico, apresentando os mesmos passos e desafios da cirurgia em humanos. Os passos cirúrgicos correspondentes à anastomose portocava e à dissecção do segmento retro-hepático da veia cava inferior exigem maior atenção por parte do cirurgião, representando excelente treinamento técnico para o transplante clínico. A sobrevida dos animais é bastante elevada, permitindo estudos experimentais envolvendo a fisiologia hepática e o transplante de fígado.

\section{REFERÊNCIAS}

1. Starzl TE, Demetris AJ, Van Thiel D. Liver transplantation. N Engl J Med 1989;321:1014-22. 
2. Starzl TE, Marchioro TL, Von Kaulla KN, Hermann G, Brittain RS, Waddell WR. Homotransplantation of the liver in humans. Surg Gynecol Obstet 1963;117:659-76.

3. Starzl TE, Gordon RD, Tzakis AG, Todo S. Transplante do fígado. In: SABISTON DC. (ed.) Tratado de Cirurgia: as bases biológicas da prática cirúrgica moderna. 14a . ed. Rio de Janeiro, Guanabara Koogan, 1993. v. 1, p. 399-408.

4. Kato T, Levi D, Nery JR, Pinna AD, Tzakis AG. Operative procedures. In: Maddrey WC, Schiff ER, Sorrell MF. (ed.) Transplantation of the liver. $3^{\text {rd }}$. ed. Philadelphia, Lippincott Williams \& Wilkins, 2001. p. 47-64.

5. Fonkalsrud EW, Ono H, Shafey OA, Longmire WP. Orthotopic canine liver homotransplantations without vena caval interruption. Surg Gynecol Obstet 1967;125:319-27.

6. Calne RY \& Williams R. Liver transplantation in man. I. Observations on technique and organization in five cases. $\mathrm{Br}$ Med J 1968;4:535-40.

7. Tzakis AG, Todo S, Starzl TE. Orthotopic liver transplantation with preservation of the inferior vena cava. Ann Surg 1989;210:649-53.

8. Nery JR, Jacque J, Weppler D, Casella J, Luque C, Siquijor A, Thompson J, Ruiz P, Khan F, Webb M, Tzakis A. Routine use of the piggyback technique in pediatric orthotopic liver transplantation. J Pediatr Surg 1996;31:1644-7.
9. Frank HA \& Jacob SW. One-stage hepatectomy in the dog, preserving the inferior vena cava. Am J Physiol 1952; 168:156-8

10. Starzl TE, Bernhard VM, Benvenuto R, Cortes N. A new method for one-stage hepatectomy for dogs. Surgery 1959;46:880-6.

11. Ellenport CR. Sistema digestivo do carnívoro. In: GETTY R. (ed.) Sisson e Grossman Anatomia dos Animais Domésticos. 5a. ed. Rio de Janeiro, Interamericana, 1981. v. 2, p. 1445-64.

12. Pomfret EA, Pomposelli JJ, Jenkins RL. Liver donor liver transplantation. J Hepatol 2001;34:613-24.

\section{Endereço para correspondência}

Orlando de Castro-e-Silva Jr.

Departamento de Cirurgia e Anatomia - FMRP - USP

Campus Universitário - Monte Alegre

14049-990 - ribeirão Preto - SP

e-mail - orlandocsj@hotmail.com

Conflito de interesse: nenhum

Fonte de Financiamento: FAPESP 